\title{
Geoambientes da Península Potter, Ilha Rei George, Antártica Marítima
}

\author{
André Medeiros de ANDRADE ${ }^{1,2}$, Jorge ARIGONY-NETO ${ }^{2,3}$, Everton Luiz POELKING ${ }^{2,4}$, Roberto \\ Ferreira Machado MICHEL ${ }^{2,5}$, Carlos Ernesto G. R. SCHAEFER ${ }^{2,6}$, Kátia Kellem da ROSA ${ }^{2,7}$ \& \\ Ulisses Franz BREMER ${ }^{2,7}$
}

${ }^{1}$ Instituto de Ciências Agrárias, Universidade Federal dos Vales do Jequitinhonha e Mucuri. Av. Vereador João Narciso, 1.380, CEP 38.610-000, Unaí, Ba, Brasil (andre.medeiros@ufvjm.edu.br).

2 Instituto Nacional de Ciência e tecnologia da Criosfera. Av. Bento Gonçalves, 9.500, CEP 91.540-000, Porto Alegre, RS, Brasil.

${ }^{3}$ Instituto de Oceanografia, Universidade Federal do Rio Grande. Av. Itália, km 8, CEP 96.201-900, Rio Grande, RS, Brasil (jorgearigony@furg.br).

${ }^{4}$ Universidade Federal do Recôncavo da Bahia. Rua Rui Barbosa, 710, CEP 44.380-000, Cruz das Almas, Ba, Brasil (everton@ufrb.edu.br).

${ }^{5}$ Departamento de Ciências Agrárias e Ambientais, Universidade Estadual de Santa Cruz. Rodovia 20 Jorge Amado, km 16, CEP 45.662-900, Ilhéus, Ba, Brasil (roberto@michel.br).

${ }^{6}$ Departamento de Solos, Universidade Federal de Viçosa. Av. Peter Henry Rolfs, s/n, CEP 36.570-900, Viçosa, MG, Brasil (carlos.schaefer@ufv.br).

7 Instituto de Geociências, Universidade Federal do Rio Grande do Sul. Av. Bento Gonçalves, 9.500, CEP 91.501-970, Porto Alegre, RS, Brasil (katia.rosa@ufrgs.br, bremer@ufrgs.br)

Andrade. A.M., Arigony-Nto, J., Poelking, E.L., Michel, R.F.M., Schaefer, C.E.G.R., Rosa, K.K., Bremer, U.F., 2018. Geoambientes da Panínsula Potter, Ilha Rei George, Antártica Marítima. Pesquisas em Geociências, 45: e0726. DOI: https://doi.org/10.22456/1807-9806.88683

Resumo. Com as mudanças climáticas na Antártica Marítima detectadas a partir de 1950, essa região tem apresentado grande interesse científico. Estudos de mapeamento dos ambientes antárticos em escalas detalhadas são limitados, principalmente devido às restrições orçamentárias e de logística. As informações geradas por mapeamentos são fundamentais para detectar variações ambientais e auxiliam na gestão do uso e ocupação da superfície terrestre. 0 objetivo deste trabalho foi identificar e mapear os geoambientes da Península Potter, Ilha Rei George, Antártica Marítima. Para isso, foram utilizadas análises multicritério com base em dados geomorfológicos, modelo de curvatura das vertentes, cobertura de vegetação e suscetibilidade à ação eólica, o que possibilitou a elaboração do zoneamento de suas principais características ambientais. Foram identificadas sete unidades geoambientais: Terraços marinhos, Área proglacial com atividade glaciofluvial, Terraços marinhos com ação antrópica, Terraços marinhos com cobertura de vegetação, Área proglacial com intensa atividade paraglacial, Área periglacial e Área glacial. A área livre de gelo da Península tem 668 ha e engloba seis geoambientes, com predomínio de relevos com formas convergentes e côncavas e vertentes com pouca ou nenhuma suscetibilidade à ação eólica. 0 sétimo geoambiente está localizado na geleira Polar Club. Os geoambientes dos terraços marinhos exibem maior biodiversidade de fauna e flora antártica, enquanto aqueles da porção interna da exibem predomínio de morainas, rochas expostas e lagos decorrentes da ablação da neve e gelo da superfície e da geleira Polar Club.

Palavras-chave. Geoambiente, Antártica, análise multicritério, SIG.

Abstract. Geoenvironments of the Potter Peninsula, King George Island, Maritime Antarctica. The scientific community has great attention in the region of the Antarctic Maritime because of the climate changes detected since 1950. Mapping studies of Antarctic environments on detailed scales are limited, mainly due to the limitations of financial resources and logistics. The information generated by mappings makes it possible to detect environmental variations and contribute to the management of land use and occupation. The aim of this work was to identify and to map the geoenvironments of the Potter Peninsula, King George Island, Maritime Antarctica. For that, multi-criteria based analysis of geomorphology, landforms, vegetation and susceptibility to wind action were used to cluster their environmental characteristics. Seven geoenvironments were identified and mapped: Marine terraces, Proglacial area with glaciofluvial action, Marine terraces with anthropic influence, Marine terraces with vegetation colonization, Proglacial area with paraglacial action, Periglacial area and Glacier area. The ice-free area of the Peninsula has 668 ha and comprises six geoenvironments, with a predominance of terrains with convergent and concave forms and little or inexistent susceptibility to wind action. The seventh geoenvironment is located on the Polar Club glacier. In general, the geoenvironments of the marine terraces have greater fauna and flora biodiversity, while those in the inner part of the peninsula showed predominance of old and young moraines, exposed rocks and lakes.

Keywords. Geoenvironment, Antarctica, Multicriteria analysis, GIS. 


\section{Introdução}

A criosfera abrange todo ambiente caracterizado pela presença de neve e gelo e exerce influência significativa no clima global (French, 2007; Turner et al., 2013). Segundo Bockheim \& Hall (2002), em toda a região da Antártica, menos de $1 \%$ de sua área apresenta superfícies livres de gelo no período de ablação, sendo que 14\% dessas áreas livres de gelo estão situadas na região da Península Antártica e suas ilhas (Bockheim \& Hall, 2002). A região da Antártica Marítima possui características climáticas e ambientais peculiares e distintas das apresentadas no restante da região da Antártica (Øvstedal \& Smith, 2001), e tem apresentado grande interesse científico, principalmente devido às variações climáticas (Turner et al., 2005; Turner et al., 2013).

Estudos ambientais desenvolvidos através de mapeamento geralmente são feitos por meio de abordagens individualizadas dos elementos ambientais. Entretanto, na superfície terrestre coexistem elementos que possuem inter-relação e são passíveis de serem analisados em conjunto a partir de métodos que estruturam e avaliam os elementos superficiais mediante a similaridade e correlação, possibilitando o agrupamento em unidades de geoambientes (Dias et al., 2002). Esta análise em conjunto possibilita identificar as feições com condições proglaciais e paraglaciais no ambiente, viabilizando o monitoramento de variações resultantes de condições proglaciais, além de auxiliar na gestão do uso e ocupação da superfície terrestre (Cooper \& Murray, 1992) de forma a reduzir os impactos nos ecossistemas terrestres.

O desenvolvimento de estudos e mapeamentos em ambientes antárticos em escalas detalhadas é limitado, principalmente em decorrência das dificuldades logísticas e dos altos custos para a realização de expedições em campo. Os avanços nos campos das geotecnologias têm sido fundamentais no estudo de ambientes periglaciais (Arigony-Neto et al., 2007; Poelking et al., 2014, 2015; Vieira et al., 2014; Andrade et al., 2015).

Este estudo teve como objetivo desenvolver o zoneamento da superfície da Península Potter a partir de unidades geoambientais, ampliando as informações em relação aos elementos que constituem sua superfície.

\section{2 Área, materiais e métodos}

\section{1 Área de estudo}

A Península Potter está localizada na Ilha Rei George, arquipélago das Ilhas Shetland do Sul, Antártica Marítima, entre o estreito de Bransfield e a passagem de Drake, entre as latitudes $62^{\circ} 13,5^{\prime}$ S e $62^{\circ} 16^{\prime} \mathrm{S}$ e longitudes $58^{\circ} 42^{\prime} 0$ e $58^{\circ} 33^{\prime} 0$ (Fig. 1). A península possui uma expressiva área livre de gelo durante o período de verão com extensão leste-oeste de $6 \mathrm{~km}$, norte-sul de 3,5 km e área de aproximadamente 713 ha. A frente da geleira Polar Club, localizada na Península Potter, assim como os demais sistemas glaciais da região, apresenta tendência de retração nos últimos 50 anos (Braun \& Gossmann, 2002; Del Valle et al., 2004; Poelking et al., 2014). A ação eólica na Península Potter está entre os principais elementos modeladores da espessura da neve, influenciando diretamente na distribuição e na deposição das camadas de neve. Os ventos são provenientes principalmente do sentido noroeste e oeste (Schloss et al., 2012), com rajadas que podem atingir velocidades superiores a $100 \mathrm{~km} / \mathrm{h}$ (Schloss et al., 1998). Durante o verão austral, em decorrência do aumento da temperatura do ar, ocorre intenso processo de ablação da neve e gelo acumulados durante o inverno, acarretando na saturação do solo e induzindo o processo de hidromorfismo temporário (Francelino et al., 2004).

O limite da Península Potter com o mar é de aproximadamente $12 \mathrm{~km}$ de extensão, composto predominantemente por terraços marinhos e superfícies de deposição de sedimentos. Também há predominância de planaltos crioplanados, encostas íngremes ao longo das praias e relevo suave no interior da península. A altimetria na área livre de gelo varia de $0 \mathrm{~m}$ no nível do mar até aproximadamente $195 \mathrm{~m}$ no ponto mais elevado no cone vulcânico Three Brothers (Braun \& Gossmann, 2002).

A vegetação da Península Potter apresenta distribuição espacial descontínua e desigual. A vegetação apresenta padrão de cobertura esparsa nas morainas localizadas próximas à geleira, enquanto nas superfícies rochosas e bem drenadas há predomínio de comunidades de liquens (Øvstedal \& Smith, 2001). As comunidades de musgos se 

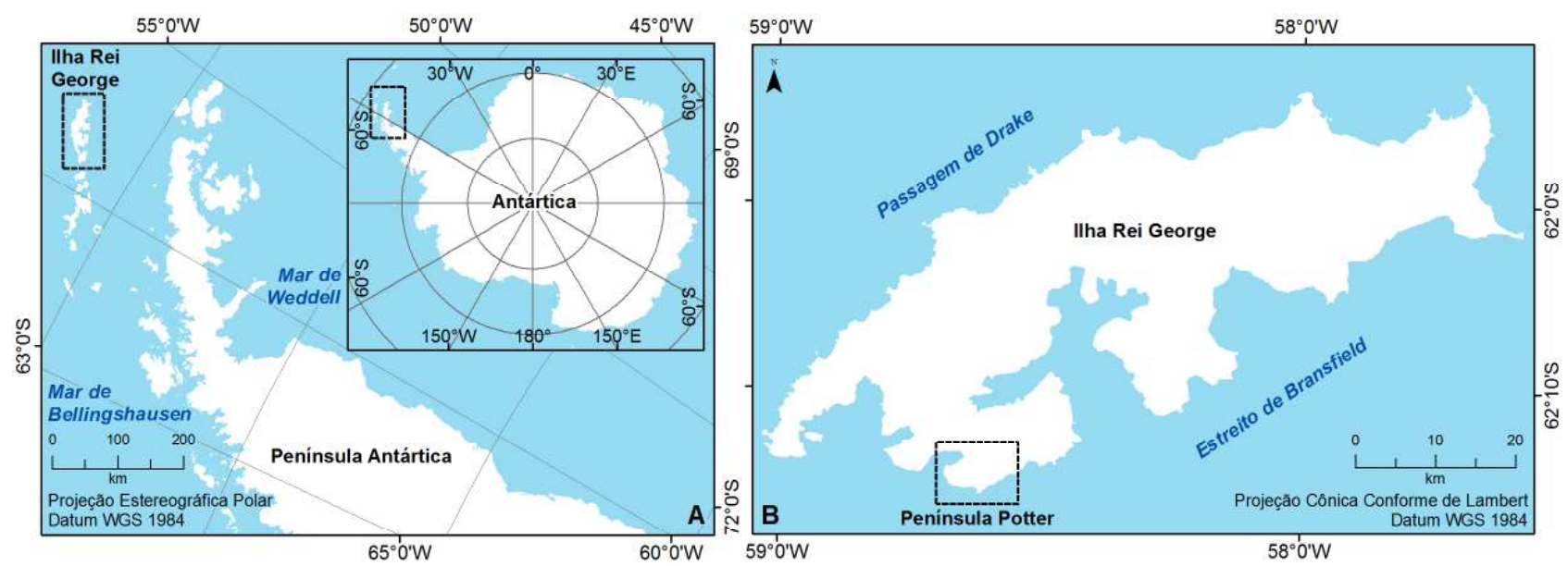

Figura 1. Mapa de localização. A) Ilha Rei George na Península Antártica; B) Península Potter na Ilha Rei George.

Figure 1. Location map. A) King George Island in the Antarctic Peninsula; B) Potter Peninsula on King George Island.

estabelecem principalmente em locais com maior umidade (Olech, 2002), além das espécies de gramíneas Deschampsia antarctica e Colobanthus quitensis com ocorrência principalmente próximo da costa ou em locais receptores de nutrientes (Schulz et al., 1998).

No interior da Península Potter existem lagos permanentes e sazonais, além de canais glaciofluviais provenientes do derretimento da neve e gelo das áreas livres de gelo e da geleira (Fig. 2). A região terrestre e os sistemas lacustres adjacentes à geleira compõem os ambientes proglaciais (Slaymaker, 2009), enquanto as regiões mais distantes exibem a transição de ambientes glaciais para não-glaciais (Slaymaker, 2009). De acordo com Del Valle et al. (2004), os lagos permanentes foram formados entre morainas neoglaciais, tendo surgido inicialmente há 500 anos o Lago Rudy e, posteriormente, na década de 1950, o Lago Superior. Este último apresentou expansão de sua área entre os anos 1981 e 1985. A área do Lago Rudy é de 88 ha e a do Lago Superior é de 21 ha. Na Península Potter foi implementada a Área Antártica Especialmente Gerenciada no 132 (ASPA no 132), com área de aproximadamente 190 ha (Schuster, 2008).

\subsection{Dados orbitais, topográficos e meteorológicos}

Para a delimitação da cobertura superficial nas áreas livres de gelo e da geleira Polar Club foram utilizados dados provenientes de sensores orbitais de natureza passiva e ativa. Para a extração de informações altimétricas e do relevo foram uti- lizados os dados da carta topográfica da Península Potter (Lusky et al., 2001).

Foi utilizada uma cena multiespectral do satélite QuickBird com data de passagem de 6 de janeiro de 2007. A cena possui quatro bandas espectrais com resolução espacial de 2,44 m e uma banda pancromática com $0,61 \mathrm{~m}$. Foram realizados os procedimentos de correção da geometria a partir de coordenadas extraídas de pontos de controle utilizando o método descrito em Richards \& Jia (2006) e posteriormente foram fusionadas as bandas multiespectrais com a banda pancromática por meio da transformação IHS descrito por Schowengerdt (2007).

Também foram utilizadas três cenas do satélite COSMO-SkyMed obtidas em 01/02/2011, 29/12/2011 e 15/02/2012, todas com polarização VV e resolução espacial de $1 \mathrm{~m}$. Essas imagens foram obtidas em nível 1A (Single-Look Complex Slant) e em cada cena foram realizados os procedimentos de calibração radiométrica a partir do padrão de iluminação da antena do satélite e utilizando informações de pontos referenciais, filtragem do speckle para redução dos ruídos e correção da geometria para minimizar os efeitos de distorção do relevo.

A partir das curvas de nível com $3 \mathrm{~m}$ de equidistância extraídas do mapa topográfico de Lusky et al. (2001) foi elaborado o modelo digital de elevação (MDE) das áreas livres de gelo da Península Potter. Para a execução do MDE foi utilizado o interpolador topo to raster, baseado no método Locally Adaptive Gridding (Hutchinson, 1989), concebido com a finalidade de elaborar in- 


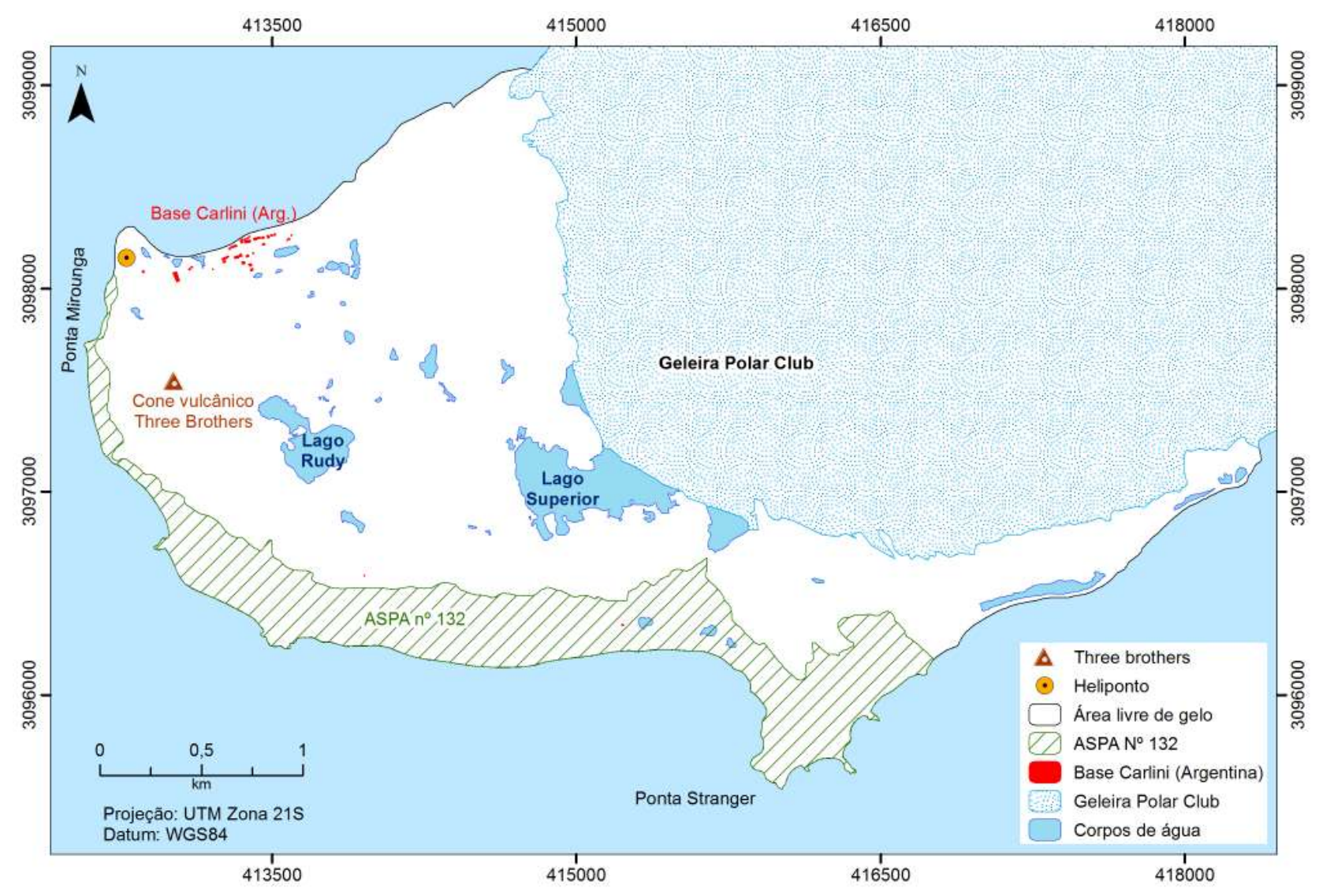

Figura 2. Principais feições fisiográficas existentes na Península Potter.

Figure 2. Prevailing physiographic features on the Potter Peninsula.

terpolações que consideram as características de drenagem e hidrografia.

Para avaliar as condições meteorológicas na Península Potter foi utilizada a série histórica registrada pela estação meteorológica permanente da Base Carlini entre 1986 e 2011. A partir desses dados foram analisadas as condições meteorológicas durante o período de obtenção dos dados desse estudo, relacionando com os padrões meteorológicos dos 25 anos de registro.

\subsection{Delimitação das unidades geoambientais}

Os dados de vegetação utilizados nesse estudo foram adaptados a partir de Poelking et al. (2015). A classificação utilizou o classificador estatístico de Máxima Verossimilhança (MAXVER) e considerou cinco classes de vegetação: algas talosas, associação de liquens e musgos, associação de musgos e gramíneas, liquens e musgos. As amostras de vegetação utilizadas para a classificação foram obtidas durante a expedição científica à Península Potter no verão de 2008 e 2012 (Fig. 3).

A delimitação das feições geomorfológicas, forma das vertentes, unidades fitofisionômicas e dos lagos foi efetuada a partir de análise multicritério, e para tal foram utilizados em conjunto os dados orbitais, o MDE e os dados coletados em campo durante o verão de 2012.

A classificação das configurações topográficas de uma superfície possibilita caracterizar as curvaturas horizontais e as curvaturas verticais (Pennock et al., 1997). Utilizando o método proposto por Moore et al. (1991) foram interseccionadas as curvaturas horizontais (convergente, divergente e planar) e as curvaturas verticais (côncava, convexa e retilínea), resultando em nove classes de curvatura das vertentes. A forma do relevo, estimada pelo modelo de curvatura das vertentes, possibilita estimar os padrões de transporte, velocidade e intensidade de fluxos superficiais em uma superfície (Dikau, 1990; Hutchinson \& Gallant, 2000).

Para delimitar as vertentes mais suscetíveis à ação eólica, primeiro fez-se a segmentação das vertentes conforme a orientação. Posteriormente, as vertentes foram classificadas conforme $\mathrm{o}$ as intensidades eólicas predominantes constatadas por Schloss et al. (1998), Wunderle et al. (1998) e Schloss et al. (2012).

As unidades geoambientais da Península 
Potter foram geradas a partir dos dados extraídos das cenas COSMO-SkyMed e QuickBird, do MDE e dos dados obtidos em campo.

Para a delimitação dos geoambientes utilizou-se a abordagem multicritério. Foram consideradas as feições geomorfológicas como a principal variável para a demarcação das áreas. Posterior- mente, foram incorporadas as variáveis: variabilidade da geleira Polar Club, cobertura de vegetação, formas de relevo (obtido pela interpretação do relevo de acordo com a declividade e modelo de curvatura horizontal e vertical das vertentes) e suscetibilidade à ação eólica (Fig. 4).

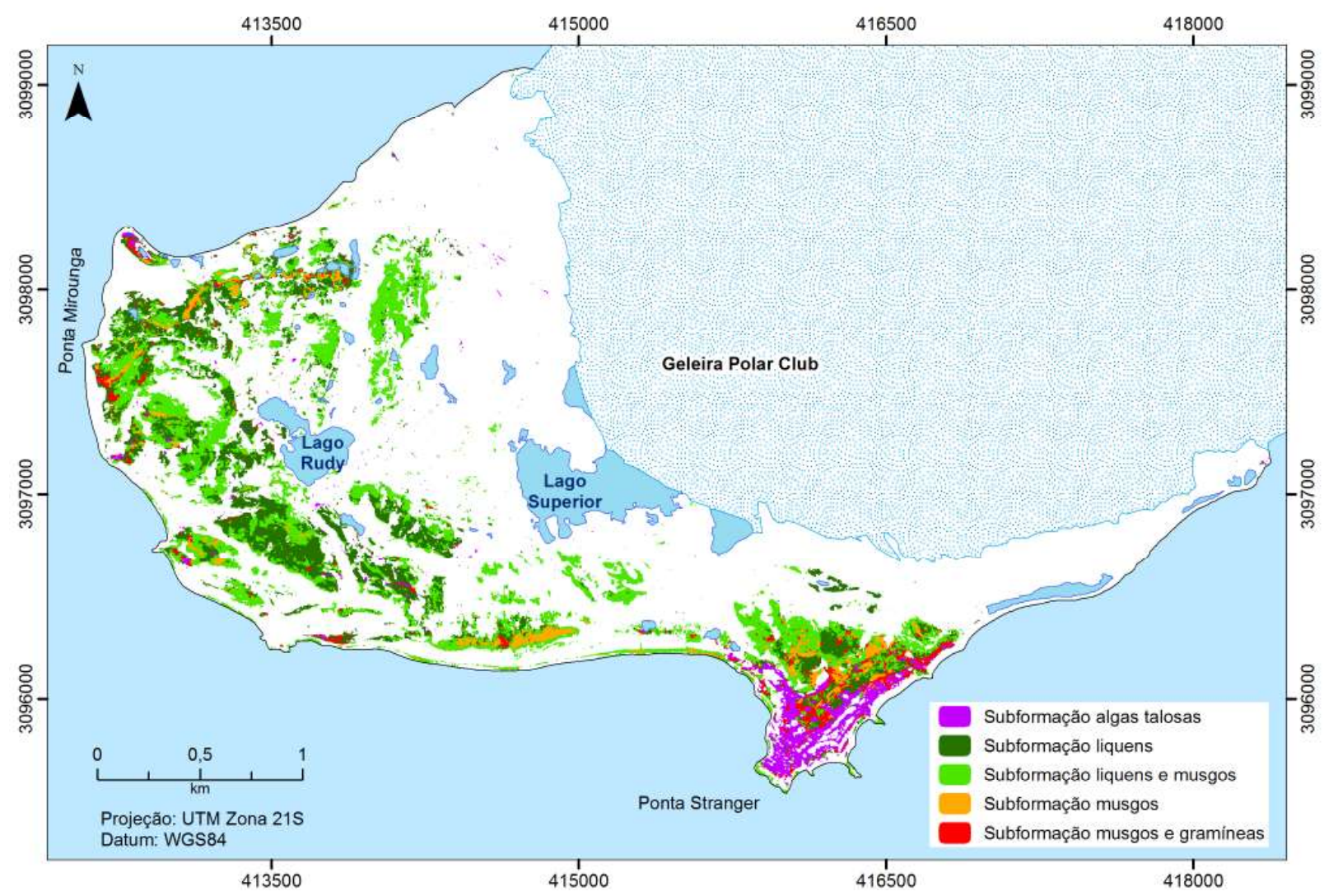

Figura 3. Mapa da cobertura de vegetação da Península Potter (Adaptado de Poelking et al. 2015). Figure 3. Map of the vegetation cover of the Potter Peninsula (Adapted from Poelking et al. 2015).

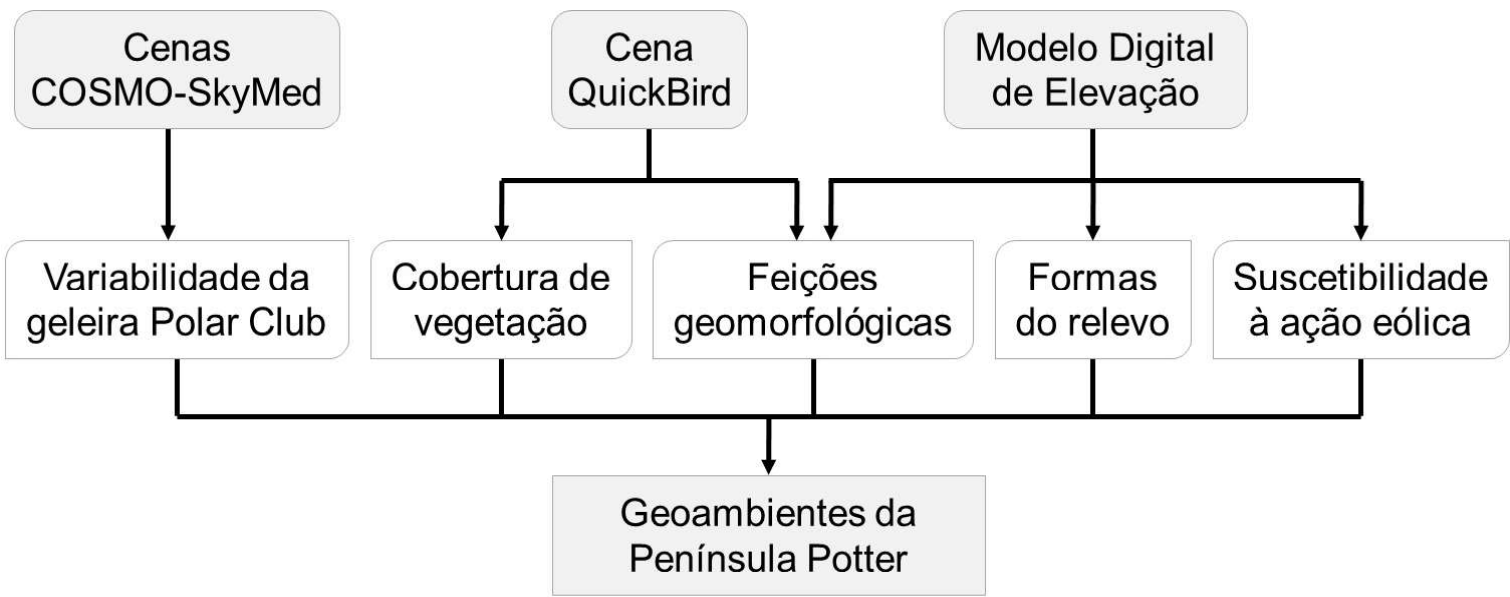

Figura 4. Conjunto de dados utilizados (COSMO-SkyMed, QuickBird e Modelo Digital de Elevação) e os produtos gerados (variabilidade da geleira, cobertura de vegetação, feições geomorfológicas, formas do relevo e suscetibilidade à ação eólica) para a delimitação dos geoambientes da Península Potter.

Figure 4. Data set used (COSMO-SkyMed, QuickBird and Digital Elevation Model) and the products generated (glacier variability, vegetation cover, geomorphological features, relief and susceptibility to wind action) to delimit the geoenvironments of the Potter Peninsula. 


\section{Resultados e discussões}

A área da Península Potter foi segmentada em dois domínios geoambientais, um abrangendo a geleira Polar Club e o outro a área livre de gelo. Esses dois domínios são englobados por sete unidades geoambientais, estando seis localizados nas áreas livres de gelo (Terraços marinhos com ação antrópica, Área proglacial com intensa atividade paraglacial, Terraços marinhos, Área periglacial, Terraços marinhos com alta cobertura de vegetação e Área proglacial com intensa atividade glaciofluvial) e o outro na geleira (Área glacial) (Fig. 5). A denominação de cada geoambiente foi gerada de acordo com os processos geomorfológicos e feições de relevo predominantes, os quais caracterizam cada setor.

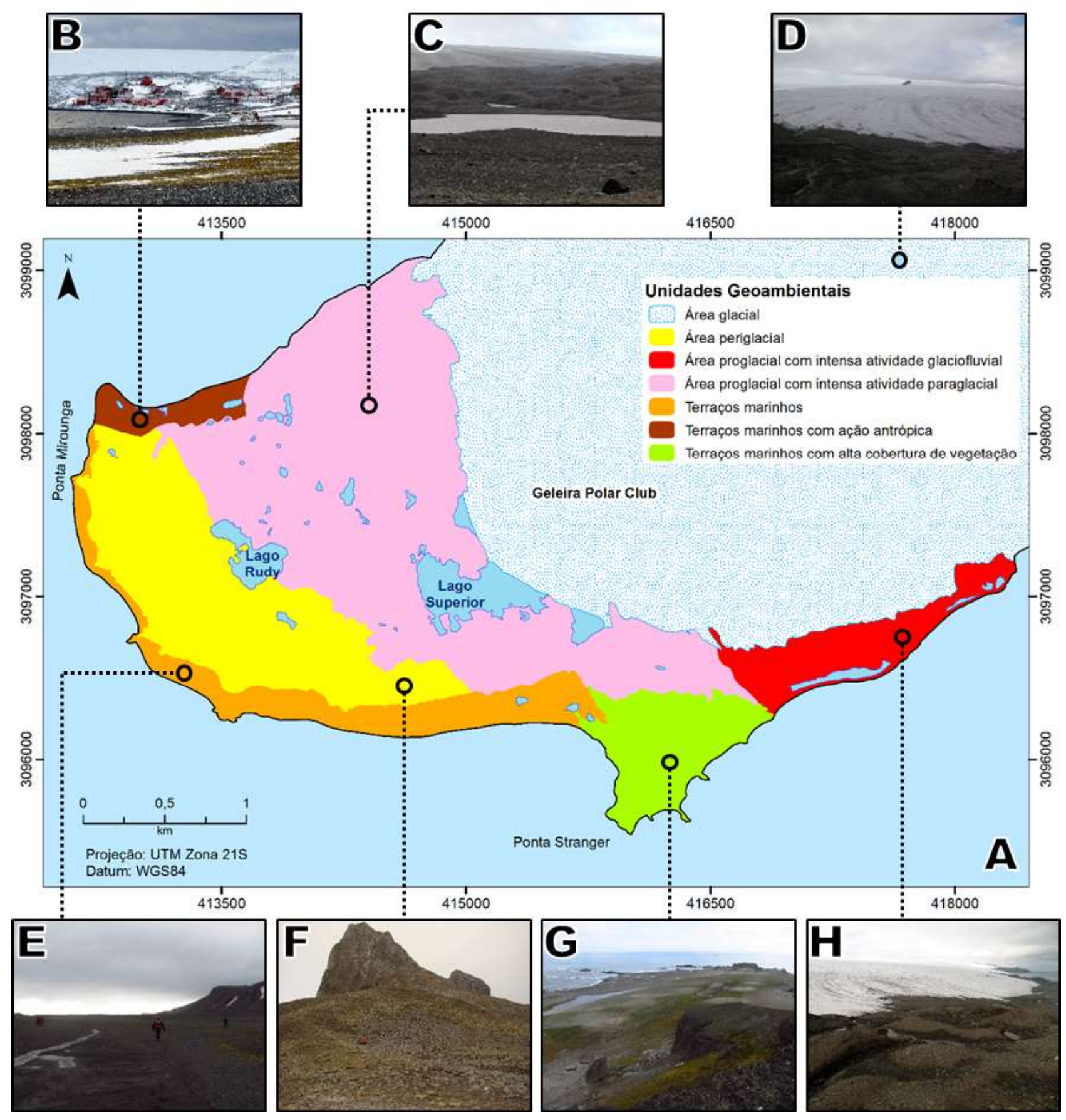

Figura 5. Geoambientes da Península Potter. A) Localização das unidades geoambientais da Península Potter; B) Terraços marinhos com ação antrópica; C) Área proglacial com intensa atividade paraglacial; D) Área glacial; E) Terraços marinhos; F) Área periglacial; G) Terraços marinhos com alta cobertura de vegetação; H) Área proglacial com intensa atividade glaciofluvial. Figure 5. Geoenvironments of the Potter Peninsula. A) Location of geoenvironments units of the Potter Peninsula; B) Raised marine terrace with anthropic influence; C) Proglacial area with paraglacial action; D) Glacial area; E) Marine terraces; F) Periglacial area; $G)$ Marine terraces with high vegetation biodiversity; $H)$ Proglacial area with glaciofluvial action. 
3.1 Geoambiente Terraços Marinhos com Ação Antrópica (TMAA)

O geoambiente Terraços Marinhos com Ação Antrópica (TMAA) (Fig. 5B) possui a área na Península Potter mais impactada por atividades antrópicas devido à presença da Base Carlini (Argentina). A geomorfologia é caracterizada pela unidade geomorfológica de planície com deposição de sedimentos de retrabalhamento marinho. As feições geomorfológicas são compostas principalmente por terraços marinhos soerguidos e terraços marinhos, abrangendo aproximadamente 65 e 26\%, respectivamente, desse geoambiente. Também ocorre em menor proporção a feição geomorfológica de aluviões, abrangendo 7,4\% da área total. Os aluviões são importantes para o ecossistema terrestre por serem compostos por detritos superficiais de frações do solo e de rochas com granulometria variáveis, transportados por canais de drenagem e acumulados nas superfícies de deposição. Por estar distante da geleira, esse geoambiente recebe pouca influência de processos proglaciais. Há lagunas no sistema costeiro e leques aluviais na desembocadura dos canais de drenagem. As formas das vertentes predominantes são convergente-côncavo e planar-retilíneo, sendo que as duas classes em conjunto englobam $72 \%$ da superfície desse geoambiente.

Uma área de aproximadamente $55 \mathrm{~m}^{2}$ no TMAA está localizada no interior da ASPA no 132 , valor insignificante em relação à proporção total da área da ASPA. A vegetação nesse geoambiente é constituída por comunidades de liquens e associação de liquens e musgos, cobrindo uma área de 1 ha e 2 ha respectivamente. A maior concentração das comunidades vegetais nesse geoambiente está localizada na superfície onde foi instalado o heliponto. A cobertura de comunidades vegetais nesse geoambiente poderá aumentar com o tempo, principalmente devido aos impactos provenientes das atividades antrópicas e com o aumento da presença de aves e mamíferos.

A enseada Potter, ao norte do geoambiente TMAA possui configuração geomorfológica que contribui para a proteção das atividades eólicas. Isso é destacado ao constatar que cerca de $34 \%$ das feições superficiais do terreno sofrem pouca ou nenhuma suscetibilidade à ação eólica. A intensidade mais elevada de susceptibilidade à ação eólica nesse geoambiente é proveniente do sentido Oeste e perfaz 10,8\% da superfície. Em decorrência da geleira Polar Club, que atua como proteção física, os ventos mais intensos e originários do sentido Leste atingem poucas vertentes nesse geoambiente. Pode-se considerar que as condições geomorfológicas, a forma do relevo e a proximidade da enseada constituem fatores que propiciaram a instalação das edificações da Base Carlini.

\subsection{Geoambiente Área Proglacial com Intensa Ativi- dade Paraglacial (APIAP)}

0 geoambiente Área Proglacial com Intensa Atividade Paraglacial (APIAP) (Fig. 5C) possui a maior área superficial e também a maior área proglacial da Península Potter. A vasta área livre de gelo faz contato direto com $64,8 \%$ da frente da geleira Polar Club, resultando na ocorrência de lagos proglaciais adjacentes à geleira e com vazão de abastecimento proveniente do derretimento na geleira. A formação deste recente geoambiente está relacionada à dinâmica de retração frontal da geleira Potter nas últimas décadas, conforme reportado por Andrade (2013), Poelking et al. (2014), Bonada et al. (2018).

A geomorfologia do geoambiente APIAP é composta principalmente por um planalto com depressões periféricas (formadas pela erosão glacial e glaciofluvial). As principais feições geomorfológicas encontradas são originadas da atividade erosiva da geleira e glaciofluvial e da atividade deposicional marginal glacial, glaciolacustre e glaciofluvial.

As morainas, resultado da atividade marginal glacial, compreendem $44,7 \%$ da área total. 0 predomínio das formas do relevo convergente-côncavo e planar-retilínea contribuem para a deposição das morainas e dos sedimentos transportados pelos canais de drenagem. Há predominância para morainas na forma de cordões lineares.

Foram registradas cristas morâinicas de avanço (mais externas e mais antigas) e de recessão (no ambiente proximal e consideradas mais recentes) neste geoambiente, o que vai de acordo com Bonada et al. (2018). As morainas de recessão 
são formadas por um longo período de estabilização de sua frente durante uma recessão glacial (Benn \& Evans, 2010). Na área de estudo, estas morainas evidenciam o contínuo processo de retração frontal, possivelmente, desde a Pequena Idade do Gelo. A moraina mais externa indica o limite máximo da geleira na última condição de avanço durante a Pequena Idade do Gelo (Bonada et al., 2018). As morainas que não são recentes estão expostas a intensa atividade de processos não-glaciais.

Andrade (2013) também evidenciou morainas de menor extensão e em forma de montículos, características do ambiente recessional proglacial que se formam quando estão em contato com o gelo, muitas vezes estagnado. Hambrey (1994) e Benn \& Evans (2010) justificam que estes montículos podem apresentar-se em pequenas e irregulares cristas e que nem sempre bem preservadas devido ao degelo sazonal.

Durante o verão, devido ao aumento da ablação na geleira nas áreas livres de gelo, são formados canais de drenagem sazonais, originando leques aluviais que alimentam lagos proglaciais ou que desaguam no sistema costeiro da enseada Potter. A erosão glaciofluvial atua de forma intensa e é decorrente da drenagem proveniente do conjunto de lagos interconectados e adjacentes ao lago Superior. Os canais glaciofluviais formam canais em forma de "v", com importante ação modeladora do terreno, além de transportar elevado volume de sedimentos da porção superior da península e posteriormente depositar nos terraços marinhos.

Em decorrência do recuo da geleira Polar Club, o geoambiente APIAP possui as áreas livres de gelo mais recentes da península, incluindo o Lago Superior que teve o início de sua formação na década de 1950 (Del Valle et al., 2004). Este ambiente é o que possui uma mais intensa atividade paraglacial devido à recente exposição dos sedimentos depositados na margem da geleira e a menor cobertura de vegetação, deixando-os susceptíveis à ação gravitacional, eólica, pluvial e ao intemperismo químico, entre outros. A descontinuidade de cordões morâinicos, verificada em campo, ocorre devido ao processo de retrabalhamento paraglacial. Outra consequência do retrabalhamento deposicional é o aumento dos depósitos de fluxos de detritos provenientes de cristas morâinicas, considerados por Ballantyne (2002) como um dos primeiros efeitos das mudanças ambientais.

As superfícies recentes dos depósitos apresentam instabilidade superficial e devido ao processo de derretimento de neve superficial ocorre a saturação do solo e consequentemente hidromorfismo temporário. Apesar dessas condições, a cobertura de vegetação nesse geoambiente é expressiva no setor mais distal da margem da geleira, englobando uma área de 30 ha, com predomínio de associação de liquens e musgos e as comunidades de liquens, abrangendo 76,2\% e 19,5\% respectivamente da área coberta por vegetação. A estabilização dos depósitos sedimentares pela cobertura vegetal indica que estas áreas passam de processos glaciais para não-glaciais e uma sucessão para o geoambiente periglacial com o tempo.

Os canais em forma de "V" também são evidenciados como atividade paraglacial e retrabalham os depósitos morâinicos. A precipitação líquida propicia a formação de canais pluviais, além de ampliar os movimentos de massa (junto aos depósitos morâinicos e picos rochosos) e intemperismo químico evidenciados neste geoambiente e nos demais. Foram evidenciadas ravinas formadas pelo fluxo convergente da água de degelo e a ação pluvial durante o verão.

Comparando com os demais geoambientes, a ação eólica nas vertentes é predominantemente de intensidade média ou de pouca ou nenhuma influência. Estas condições podem ser decorrentes da sua posição geográfica, que possui a superfície mais elevada em relação ao nível do mar, havendo contensão física pelas encostas dos terraços marinhos costeiros e também pela geleira Polar Club em toda a sua porção leste.

\subsection{Geoambiente Terraços Marinhos (TM)}

O geoambiente Terraços Marinhos (TM) (Fig. 5E) possui o relevo predominantemente plano e marcado por áreas de deposição de sedimentos provenientes do interior da península. Esses sedimentos são transportados principalmente por canais de degelo, formando os terraços marinhos de deposição glaciofluviais (Slaymaker, 2009).

A geomorfologia é composta principalmente por uma planície deposicional praial ao longo da depressão periférica. As principais fei- 
ções geomorfológicas encontradas, além do depósito de sedimentos marinhos, são as originadas da atividade erosiva da geleira e glaciofluvial não recente. Atividade periglacial é observada. Também há ocorrência em menor proporção de depósito de tálus oriundos do geoambiente adjacente que possui predomínio de afloramentos rochosos com rochas com menores partículas granulométricas que são transportadas através das encostas íngremes que dividem os dois geoambientes. A forma predominante da curvatura das vertentes é a convergente-côncava, abrangendo $41 \%$ da superfície total, sendo que essa forma possui o tipo de curvatura propicia a máxima concentração e acúmulo dos materiais transportados na superfície.

Os TM são áreas fundamentais para a manutenção do ecossistema da Península Potter. Da área total da ASPA nํㅜㄹㄹ 43,4\% está no interior desse geoambiente. A vegetação classificada abrange uma área de 14 ha, sendo 71,3\% composta por comunidades de liquens e musgos. A gestão desse geoambiente é essencial devido à ocorrência de superfícies colonizadas por vegetação e a presença de pinguins, elefantes e lobos marinhos próximos à costa marítima durante o verão, garantindo a manutenção e preservação da biodiversidade de fauna e vegetação do ecossistema local.
A orientação predominante das vertentes acarreta em pouca susceptibilidade à ação eólica. As classes predominantes de influência eólica no geoambiente TM são de pouca ou nenhuma intensidade e de intensidade média com direção noroeste-sudoeste, abrangendo aproximadamente $45 \%$ e $27 \%$ respectivamente da área superficial total do geoambiente. Estima-se que $11,8 \%$ das vertentes recebem intensa influência eólica com origem oeste.

A tabela 1 sintetiza as características das unidades geoambientais delimitadas na Península Potter.

\subsection{Geoambiente Área Periglacial (AP)}

O geoambiente Área Periglacial (AP) (Fig. 5F) possui predomínio de características de ambientes periglaciais, porém com o ambiente não glacial condicionado por processos de glaciação (Slaymaker, 2009).

A geomorfologia é composta principalmente por unidade de planalto (central na Península) e depressão periférica. Os afloramentos rochosos e as superfícies cobertas por tálus com fragmentos de rochas em cone compõem as principais feições geomorfológicas desse geoambiente. Tais feições

Tabela 1. Principais características das Unidades Geoambientais da Península Potter, Ilha Rei George, Antártica Marítima. Table 1. Main features of Geoenvironmental Units of the Potter Peninsula, King George Island, Antarctica Maritime.

\begin{tabular}{|c|c|c|c|c|c|c|c|}
\hline Geoambiente & Sigla & Feições geomorfológicas & $\begin{array}{l}\text { Curvatura da } \\
\text { vertente }\end{array}$ & $\begin{array}{l}\text { Relevo pela } \\
\text { Declividade }\end{array}$ & Vegetação & $\begin{array}{l}\text { Área } \\
\text { (ha) }\end{array}$ & $\begin{array}{c}\text { Principais } \\
\text { feições glaciais }\end{array}$ \\
\hline Área glacial & $\mathrm{AG}$ & Geleira & $\begin{array}{l}\text { Retilíneo e } \\
\text { planar | } \\
\text { Côncavo e } \\
\text { planar }\end{array}$ & Ondulado & Inexistente & 829 & Sistema glacial \\
\hline Área periglacial & AP & $\begin{array}{l}\text { Afloramento rochoso } \\
\text { Cone de detritos }\end{array}$ & $\begin{array}{l}\text { Convergente e } \\
\text { côncavo | } \\
\text { Divergente e } \\
\text { convexo }\end{array}$ & Ondulado & $\begin{array}{l}\text { Líquens e } \\
\text { musgos | } \\
\text { Liquens }\end{array}$ & 156 & $\begin{array}{l}\text { Predomínio de } \\
\text { condições } \\
\text { periglaciais }\end{array}$ \\
\hline $\begin{array}{l}\text { Área Proglacial com } \\
\text { intensa atividade para } \\
\text { glacial }\end{array}$ & APIAP & $\begin{array}{l}\text { Cordões morâinicos } \\
\text { frontaisde recessão e de } \\
\text { avanço }\end{array}$ & $\begin{array}{l}\text { Convergente e } \\
\text { côncavo | Planar } \\
\text { e retilíneo }\end{array}$ & Ondulado & $\begin{array}{l}\text { Liquens e } \\
\text { musgos }\end{array}$ & 332 & $\begin{array}{l}\text { Lagos proglaciais } \\
\text { adjacentes à geleira e } \\
\text { morainas recentes }\end{array}$ \\
\hline $\begin{array}{l}\text { Área Proglacial com } \\
\text { atividade glaciofluvial }\end{array}$ & APIAG & $\begin{array}{l}\text { Cone de deposição de } \\
\text { sedimentos glaciofluviais | } \\
\text { Morainas de recessão }\end{array}$ & $\begin{array}{l}\text { Convergente e } \\
\text { côncavo | Planar } \\
\text { e convexo }\end{array}$ & $\begin{array}{l}\text { Ondulado | Suave } \\
\text { ondulado }\end{array}$ & $\begin{array}{l}\text { Vegetação } \\
\text { esporádica }\end{array}$ & 48 & $\begin{array}{l}\text { Morainas recentes e } \\
\text { canais de drenagem } \\
\text { da ablação na geleira }\end{array}$ \\
\hline Terraços marinhos & $\mathrm{TM}$ & Terraços marinhos & $\begin{array}{l}\text { Convergente e } \\
\text { côncavo | Planar } \\
\text { e retilíneo }\end{array}$ & Suave ondulado & $\begin{array}{l}\text { Liquens e } \\
\text { musgos }\end{array}$ & 63 & $\begin{array}{l}\text { Canais fluviais e } \\
\text { atividade periglacial }\end{array}$ \\
\hline $\begin{array}{l}\text { Terraços marinhos } \\
\text { com ação antrópica }\end{array}$ & TMAA & $\begin{array}{l}\text { Terraços marinhos } \\
\text { soerguidos }\end{array}$ & $\begin{array}{l}\text { Convergente e } \\
\text { côncavo | Planar } \\
\text { e retilíneo }\end{array}$ & $\begin{array}{l}\text { Suave ondulado | } \\
\text { Plano }\end{array}$ & $\begin{array}{l}\text { Líquens e } \\
\text { musgos | } \\
\text { Liquens }\end{array}$ & 17 & $\begin{array}{l}\text { Poucas } \\
\text { características } \\
\text { proglaciais }\end{array}$ \\
\hline $\begin{array}{l}\text { Terraços marinhos } \\
\text { com cobertura de } \\
\text { vegetação }\end{array}$ & TMCV & Terraços marinhos & $\begin{array}{l}\text { Convergente e } \\
\text { côncavo | Planar } \\
\text { e retilíneo }\end{array}$ & Suave ondulado & $\begin{array}{l}\text { Liquens e } \\
\text { musgos | Algas } \\
\text { talosas }\end{array}$ & 56 & $\begin{array}{l}\text { Predomínio de } \\
\text { condições } \\
\text { periglaciais }\end{array}$ \\
\hline
\end{tabular}


geomorfológicas em conjunto com o cone vulcânico Three Brothers e as encostas rochosas geram superfícies cobertas por fragmentos de rochas de tamanho e granulometria variados. Nesse geoambiente está localizado o sistema lacustre do Lago Rudy que é abastecido por canais de drenagem e pelo degelo da camada ativa do permafrost e da neve e gelo superficial. A forma do relevo predominante é a convergente-côncavo, englobando 39,1\% da área total desse geoambiente. Essa configuração predominante da forma do relevo contribui para a deposição de fragmentos de rochas, sendo assim associadas às feições geomorfológicas dos terraços marinhos soerguidos. Os relevos com forma divergente-convexa também possuem área expressiva, contribuindo para o transporte dos fragmentos de rochas para os terraços marinhos.

A área da ASPA no 132 no interior do geoambiente AP é de 35 ha, representando 24,1\% de sua área total. A área nesse geoambiente coberta por vegetação é de 70 ha, correspondendo ao geoambiente com a maior cobertura superficial de vegetação na Península.

3.5 Geoambiente Terraços Marinhos com Alta Cobertura de Vegetação (TMCV)

0 geoambiente Terraços Marinhos com Alta Cobertura de Vegetação (TMCV) (Fig. 5G) está localizado na porção sul da Península Potter, incluindo a Ponta Stranger, local onde está situada a maior biodiversidade de vegetação no ecossistema dessa península. A elevada biodiversidade é favorecida pela predominância de terraços marinhos ricos em nutrientes provenientes principalmente dos vertebrados marinhos que periodicamente instalam suas colônias para reprodução, descanso e troca de pele e penas nessa área (Tatur, 2002).

A geomorfologia é composta principalmente por uma planície deposicional praial ao longo da depressão periférica. As feições geomorfológicas encontradas, com área considerável, são a de afloramento rochoso e os terraços marinhos soerguidos, englobando respectivamente $20,4 \%$ e $11,6 \%$ da área total. As formas das vertentes predominantes são do tipo convergente-côncavo e planares -retilíneas, que fornecem condições propicias para o estabelecimento de colônias de fauna. Nesse geoambiente também ocorrem em menor proporção algumas características de ambientes paraglaciais como detritos de cone, encostas rochosas e sistemas glaciolacustres (Slaymaker, 2009) e também de ambientes periglaciais.

0 geoambiente TMCV é importante para a manutenção da biodiversidade do ecossistema terrestre na Península Potter, possuindo $73 \%$ de sua área localizada no interior da ASPA nำ132. Outro fator que destaca a importância desse geoambiente é sua área de 37 ha de cobertura de vegetação, representando a segunda maior cobertura superficial de vegetação entre os geoambientes da Península Potter. Esse é o único geoambiente que possui as cinco classes de vegetação identificadas na área livre de gelo da Península Potter. As classes com maior área de cobertura são: associação de liquens e musgos e comunidade de Algas Talosas, que cobrem $38,7 \%$ e $32,6 \%$ respectivamente da área total desse geoambiente.

No TMCV ocorre predominância de suscetibilidade à ação eólica de intensidade média, com ventos de origem nordeste e sudeste, ou pouca ou nenhuma susceptibilidade à ação eólica. As duas classes abrangem $61,1 \%$ da superfície das vertentes desse geoambiente. A baixa susceptibilidade à ação eólica também contribui para a sua maior biodiversidade.

\subsection{Geoambiente Área Proglacial com Intensa Ativi- dade Glaciofluvial (APIAG)}

O geoambiente Área Proglacial com Intensa Atividade Glaciofluvial (APIAG) (Fig. 5H) está localizado em uma área de planície deposicional, pois possui predominância de feições geomorfológicas de cones de deposição de sedimento fluvial e ainda há morainas frontais recentes (retrabalhadas pelo fluxo glaciofluvial), abrangendo respectivamente $42,6 \%$ e 39,8\% da área total. Esse padrão de deposição de morainas é influenciado pelo contato direto com 2,6 km da frente da geleira Polar Club, totalizando $35,2 \%$ da extensão total. A forma das vertentes predominante é a convergente-côncavo, constituindo um fator preponderante para que o material detrítico e os sedimentos fluviais transportados através do escoamento nos canais de drenagem sejam depositados nos deltas próximos às morainas. Esses materiais depositados e pequenos lagos provenientes do derretimento 
da geleira são as principais características proglaciais. Não são observadas feições deposicionais subglaciais glaciofluviais, como eskers e flutings, o que pode ser evidência da atividade paraglacial na área.

0 geoambiente APIAG não possui área no interior da ASPA no 132, e também não foi detectada vegetação através da classificação da cena QuickBird (Poelking et al., 2015). Entretanto, no mapeamento realizado em campo, constatou-se que a ocorrência de cobertura esporádica de vegetação ainda no estágio inicial de colonização, ocorrendo principalmente na superfície das morainas estáveis. A incipiente ocorrência de vegetação nessa região deve-se ao fato de ser uma área livre de gelo recente e com superfícies instáveis, ainda configurando um ambiente de difícil desenvolvimento de comunidades vegetais.

\subsection{Geoambiente Área Glacial (AG)}

O geoambiente Área Glacial (AG) (Fig. 5D) é compreendido em sua totalidade pela geleira Polar Club, um sistema com altitude máxima de $460 \mathrm{~m}$ e altitude média de $243 \mathrm{~m}$ (Braun \& Gossmann, 2002). Dentre as feições visíveis na geleira, destaca-se o Nunatak Florence, localizado a aproximadamente $280 \mathrm{~m}$ de altitude. Essa geleira tem apresentado franco retrocesso durante os últimos 50 anos (Del Valle et al., 2004), tendo sido registrado entre 1986 e 2008 aumento de 26,5\% da área livre de gelo da Península Potter (Poelking et al., 2014). A geleira Polar Club apresentou a maior redução de área dentre as geleiras da Ilha Rei George (Braun \& Gossmann, 2002, Del Valle et al., 2004; Poelking et al., 2014), resultando no surgimento de novas áreas livres de gelo e na ampliação dos lagos proglaciais que são abastecidos principalmente pela ablação da geleira.

A superfície da geleira Polar Club apresentou variação espacial e temporal. A superfície da geleira é composta predominantemente por zonas de neve úmida e zonas de gelo exposto. Estas variações estão relacionadas às condições sazonais e com as condições meteorológicas.

Na superfície do geoambiente AG houve variação entre fevereiro de 2011 e fevereiro de 2012, com redução da zona de neve úmida e, em paralelo, aumento das zonas de gelo exposto. A área das zonas de neve úmida em fevereiro de 2011 foi de 660 ha, enquanto em dezembro de 2011 foi 380 ha e em fevereiro de 2012 foi 70 ha, significando redução de 89,4\% das zonas de neve úmida no intervalo de um ano. Nesse mesmo período, as zonas de gelo exposto registraram expansão de $84,1 \%$, passando de 110 ha em fevereiro de 2011 para 690 ha em fevereiro de 2012. A variabilidade da zona superficial da geleira interfere diretamente no escoamento de água proveniente do degelo para as áreas livres de gelo. A estação com maior intensidade de runoff ocorre durante a fase de intensa ablação (French, 2007), sendo que durante esse período a geleira se comporta como reservatório continuamente drenado através dos canais formados em sua extremidade (Cuffey \& Paterson, 2010).

A altitude é um fator com potencial de interferir na posição dos limites das zonas superficiais das geleiras (Rau et al., 2000; Arigony-Neto et al., 2009). A porção da geleira Polar Club exibida nas imagens COSMO-SkyMed utilizadas neste estudo possui altimetria máxima de $250 \mathrm{~m}$ (Fig. 6).

A zona de gelo exposto em fevereiro de 2011 concentrou-se na porção sudeste da geleira, principalmente entre 50 e $200 \mathrm{~m}$ de altitude. Em dezembro de 2011, a zona de gelo exposto apresentou expansão, porém, mantendo-se concentrada de $50 \mathrm{~m}$ e $200 \mathrm{~m}$ de altitude. Em fevereiro de 2012 aproximadamente $91 \%$ da superfície da geleira é caracterizada por zonas de gelo exposto, com a ocorrência de zonas de neve úmida apenas em altitudes superiores à $200 \mathrm{~m}$.

A redução das zonas de neve úmida ocorreu com maior intensidade entre dezembro de 2011 e fevereiro de 2012, período correspondente ao verão. A temperatura média do ar na Península Potter nos meses de dezembro, janeiro e fevereiro entre os anos de 1986 e 2012 foi $1,9^{\circ} \mathrm{C}$, enquanto a média da temperatura do ar em dezembro de 2011, janeiro e fevereiro de 2012 foi $1,93 \stackrel{\circ}{\circ}$, temperaturas superiores às médias desses períodos nos últimos 26 anos. Os padrões de expansão e retração das zonas de gelo exposto e de neve úmida apresentam variação superficial inversa, com os valores de aumento da zona de gelo exposto semelhantes aos valores de redução da zona de neve úmida. Essas variações são decorrentes das configurações glaciológicas, da baixa altitude e das condições climáticas, podendo ser reflexo de eventos sazonais e cíclicos. 


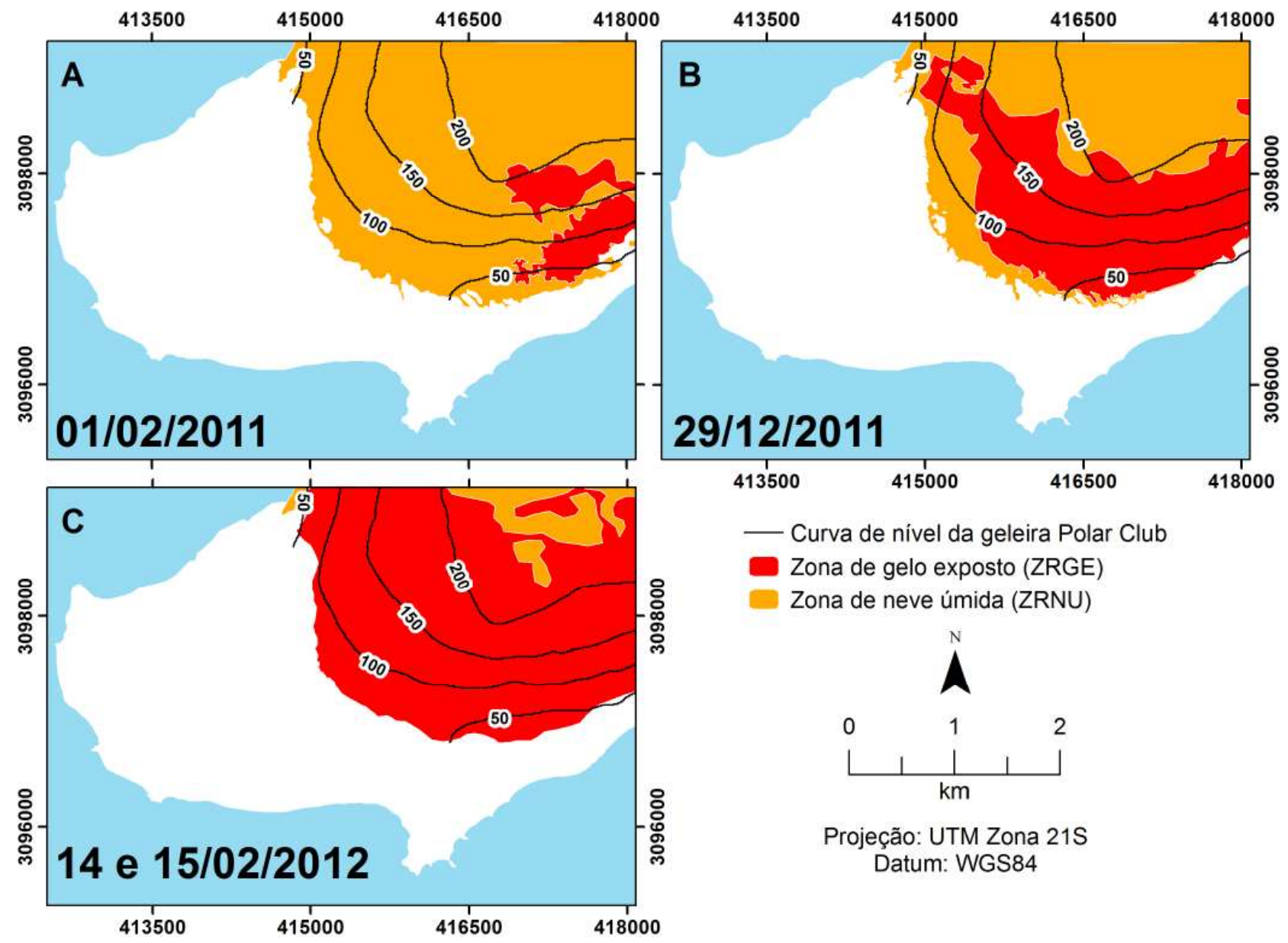

Figura 6. Variações na superfície da geleira Polar Club. A) fevereiro de 2011; B) Dezembro de 2011; C) Fevereiro de 2012. As curvas de nível com equidistância de $50 \mathrm{~m}$ possibilitam visualizar as variações de acordo com a cota altimétrica.

Figure 6. Variations in surface of Polar Club Glacier. A) February of 2011; B) December of 2011; C) February of 2012. The contour lines with equidistance of $50 \mathrm{~m}$ show the variations according to altitude.

\section{Conclusões}

O zoneamento da Península Potter através da abordagem geoambiental propiciou ampliar o acervo de dados cartográficos e a compilação das características geomorfológicas e da cobertura da vegetação em cada geoambiente delimitado. A Península Potter foi segmentada em sete unidades geoambientais, sendo seis nas áreas livres de gelo e uma na geleira Polar Club.

Dentre os geoambientes, a geleira Polar Club apresentou a maior variação espaço-temporal em decorrência da sensibilidade do ponto de fusão observada na neve e gelo que ocorrem na superfície da geleira. Os geoambientes de Área proglacial com intensa atividade paraglacial e Área Proglacial com intensa atividade glaciofluvial, por serem adjacentes à geleira são os que possuem maior relação com a dinâmica da geleira. A forte influência da geleira nestes geoambientes é evidenciada pela formação dos lagos proglaciais e dos depósitos se- dimentares originados pelos canais glaciofluviais e pela presença de morainas.

A forma de curvatura das vertentes predominante na área livre de gelo da Península Potter é a convergente-côncavo, abrangendo 296 ha. A delimitação das vertentes e suas respectivas orientações possibilitou estimar o impacto potencial da ação eólica e a respectiva suscetibilidade à ação eólica, tendo sido constatado que $31,3 \%$ das vertentes estão sujeitas à ação eólica de pouca ou nenhuma intensidade. As vertentes orientadas para Leste ou Oeste são mais suscetíveis à ação eólica intensa, enquanto as vertentes orientadas para Nordeste, Noroeste, Sudeste e Sudoeste são suscetíveis à ação eólica de média suscetibilidade, enquanto as vertentes orientadas para Norte e Sul são suscetíveis à ação eólica com menores intensidades.

Há a evidência da evolução do ambiente periglacial, com a sucessão dos ambientes de proglacial para periglacial. No geoambiente perigla- 
cial há poucos processos paraglaciais e ausência de atividade proglacial direta na área de estudo. Os processos paraglaciais, como movimentos de massa, se tornam menos intensos devido a presença de cobertura vegetal mais desenvolvida.

Novos lagos têm surgido e outros aumento de área no ambiente proglacial proximal devido a conectividade com canais glaciofluviais e degelo sazonal da geleira. Com o aumento de área os lagos podem romper-se e gerar fluxos de água e alagamento na Península. A conectividade dos lagos diminui em direção ao ambiente periglacial e muitos podem se extinguir.

A sucessão de ambientes e a alteração no sistema de drenagem podem afetar os ecossistemas existentes. Áreas de maior desenvolvimento de drenagem, observadas nos geoambientes proglaciais, tem maior umidade, enquanto que nos geoambientes onde a drenagem glaciofluvial poderá diminuir, com a perda de conectividade com a geleira, terão menor umidade.

A identificação dos ambientes mais dinâmicos neste estudo possibilita delimitar as áreas de maior interesse no monitoramento de variações proglaciais, além de auxiliar na gestão do uso do solo, minimizando os impactos nos ecossistemas terrestres da Península Potter. 0 geoambiente mais dinâmico é o mais recentemente livre de gelo e corresponde aos proglaciais, com destaque para os setores proximais com processos paraglaciais ativos. Esses setores marginais ao gelo são áreas de especial interesse científico, por revelar as condições e mudanças da geleira, e devem ser preservados. Nos geoambientes proglaciais as áreas mais íngremes são as mais dinâmicas e também há um processo de incisamento vertical progressivo junto a feições glaciofluviais e ravinamentos. As áreas mais íngremes podem progredir em profundidade e provocar a instabilidade das vertentes (margens associadas) e há processos não-glaciais, como movimentação de massa, que podem ser retomados. 0 desenvolvimento da cobertura vegetal condiciona a frequência destes processos na área de estudo, e, assim, tornam os ambientes proglaciais distais e os periglaciais menos suscetíveis à ocorrência de movimentos de massa.

Analisar os elementos que constituem os geoambientes da Península Potter gerou importantes informações acerca das características des- se ambiente. Os resultados desse estudo ampliam as informações de regiões periglaciais, apontando as áreas caracterizadas por condições proglaciais e paraglaciais. Essas informações podem contribuir para a gestão das atividades realizadas na Península Potter, sejam para fins científicos ou para uso do solo por parte da base Carlini.

Agradecimentos. Os autores agradecem à Agência Espacial Italiana (ASI) pela disponibilização das cenas do satélite COSMO-SkyMed, à Coordenação de Aperfeiçoamento de Pessoal de Nível Superior (CAPES) e ao Conselho Nacional de Desenvolvimento Científico e Tecnológico (CNPq) pelo financiamento desse estudo. À Marinha do Brasil pelo apoio logístico e ao Instituto Antártico Argentino pelo apoio durante as atividades de campo.

\section{Referências bibliográficas}

Andrade, A.M. 2013. Delimitação de geoambientes na península Potter, Ilha Rei George (Antártica Marítima), utilizando dados COSMO-SkyMed $e$ QuickBird. Porto Alegre, 150p. Dissertação de Mestrado, Programa de Pós-graduação em Sensoriamento Remoto, Instituto de Geociências, Universidade Federal do Rio Grande do Sul.

Andrade, A.M., Arigony-Neto, J., Bremer, U.F., Michel, R.F.M., Fassoni-Andrade, A.C., Schaefer, C.E.G.R. \& Simões, J.C. 2015. Cosmo-SkyMed X-band SAR data for classification of ice-free areas and glacier facies on Potter Peninsula, King George Island Antarctica. Geocarto International, 31(7): 803-812.

Arigony-Neto, J., Rau, F., Saurer, H., Jaña, R., Simões, J.C. \& Vogt, S. 2007. A times series of SAR data for monitoring changes in boundaries of glacier zones on the Antarctic Peninsula. Annals of Glaciology, 46(1): 55-60.

Arigony-Neto, J., Saurer, H., Simões, J.C., Rau, F., Jaña, R., Vogt, S. \& Gossmann, H. 2009. Spatial and temporal changes in dry-snow line altitude on the Antarctic Peninsula. Climatic Change, 94(1-2): 19-33.

Ballantyne, C.K. 2002. Paraglacial Geomorphology. Quaternary Science Reviews, 21(18-19): 19352017. 
Benn, D.I. \& Evans, D.J.A. 2010. Glaciers and Glaciation. London, Hodder Education, 802p.

Bockheim, J.G. \& Hall, K.J. 2002. Permafrost, activelayer dynamics and periglacial environments of continental Antarctica. South African Journal of Science, 98(1-2): 82-90.

Bonada, B., Rosa, K.K. \& Andrade, A.M. 2018. Caracterização geomorfológica das áreas livres de gelo em resposta da tendência de retração da geleira Polar Club, Península Potter, Ilha Rei George, Antártica. Revista Brasileira de Geomorfologia, 19(1): 149-167.

Braun, M. \& Gossmann, H. 2002. Glacial Changes in the Areas of Admiralty Bay and Potter Cove, King George Island, Maritime Antarctica. In: Beyer, L. \& Bölter, M. (Eds.). Geoecology of Antarctic IceFree Coastal Landscapes. New York, Springer, p. 75-90.

Cooper, A. \& Murray, R. 1992. A structured method of landscape assessment and countryside management. Applied Geography, 12(4): 319338.

Cuffey, K.M. \& Paterson, W.S.B. 2010. The Physics of Glaciers. Oxford, Butterworth-Heinemann, $715 \mathrm{p}$.

Del Valle, R.A., Tatur, A., Lusky, J.C. \& Gomez Izquierdo, D.R. 2004. Cambios morfológicos recientes en lagos de la Península Potter, islã 25 de Mayo, islas Shetland del Sur, Antártida. Revista de la Asociación Geológica Argentina, 59(3): 443-450.

Dias, H.C.T., Fernandes Filho, E.I., Schaefer, C.E.G.R., Fontes, L.E.F. \& Ventorim, L.B. 2002. Geoambientes do Parque Estadual do Ibitipoca, município de Lima Duarte-MG. Revista Árvore, 26(6): 777-786.

Dikau, R. 1990. Derivatives from detailed geoscientific maps using computer methods. Zeitschrift Für Geomorphologie, 80: 45-55.

Francelino, M.R., Schaefer, C.E.G.R., Fernandes Filho, E.I., Albuquerque Filho, M.R., Simas, F.N.B. \& Moreira, G.F. 2004. Geoformas da península Keller, Antártica Marítima: subsídios ao monitoramento ambiental. In: Schaefer, C.E.G.R., Francelino, M.R., Simas, F.N.B. \& Albuquerque Filho, M.R. (Eds.). Ecossistemas costeiros e monitoramento ambiental da Antártica marítima: Baía do Almirantado, IIha
Rei George. Viçosa, NEPUT, p. 16-25.

French, H.M. 2007. The Periglacial Environment. Otawa, John Wiley \& Sons, 480p.

Hambrey, M. 1994. Glacial Environments. London, UCL Press, 296p.

Hutchinson, M.F. \& Gallant, J.C. 2000. Digital Elevation Models and Representation of Terrain Shape. In: Wilson, J.P. \& Gallant, J.C. (Eds.). Terrain Analysis principles and applications. New Jersey, Wiley, p. 29-50.

Hutchinson, M.F. 1989. A new procedure for gridding elevation and stream line data with automatic removal of spurious pits. Journal of Hydrology, 106(1-3): 211-232.

Lusky, J.C., Vallverdú, R.A., Gómez Izquierdo, D.R., del Valle, R.A. \& Felske, H. 2001. Mapa digital del península Potter isla 25 de Mayo (King George Island). Buenos Aires, Instituto Antártico Argentino, 10p.

Moore, I.D., Grayson, R.B. \& Ladson, A.R. 1991. Digital Terrain Modelling: a review of hydrological, geomorphological, and biological applications. Hydrological Processes, 5(1): 3-30.

Olech, M. 2002. Plant Communities on King George Island. In: Beyer, L. \& Bölter, M. (Eds.). Geoecology of Antarctic Ice-Free Coastal Landscapes. New York, Springer, p. 215-232.

Øvstedal, D.O. \& Smith, R.I.L. 2001. Lichens of Antarctica and South Georgia: A guide to their Identification and Ecology. Cambridge, Cambridge University Press, 453p.

Pennock, D.J., Zebarth, B.J. \& De Jong, E. 1997. Landform Classification and Soil Distribution in Hummocky Terrain, Saskatchewan, Canada. Geoderma, 40(3-4): 297-315.

Poelking, E.L., Andrade, A.M., Vieira, G.B., Schaeffer, C.E.G.R. \& Fernandes Filho, E.I. 2014. Variações da frente da geleira Polar Club, península Potter, entre 1986 e 2010. Revista Brasileira de Meteorologia, 29(3): 379-388.

Poelking, E.L., Schaefer, C.E.G.R., Fernandes Filho, E.I., Andrade, A.M. \& Spielmann, A.A. 2015. Soil-landform-plant-community relationships of a periglacial landscape on Potter Peninsula, maritime Antarctica. Solid Earth, 6(2): 583-594.

Rau, F., Braun, M., Saurer, H., Gossmann, H., Kothe, G., Weber, F., Ebel, M. \& Beppler, D. 2000. Monitoring Multi-Year Snow Cover Dynamics 
on the Antarctic Peninsula Using SAR Imagery. Polarforschung, 67(1/2): 27-40.

Richards, J.A. \& Jia, X. 2006. Remote Sensing Digital Image Analysis: An Introduction. Berlin, Springer-Verlag, 454p.

Schloss, I., Ferreyra, G. \& Kloser, H. 1998. Seasonal Variation of the Conditions for Phytoplankton Growth in Potter Cove. In: Wiencke, C., Ferreyra, G., Arntz, W. \& Rinaldi, C. (Eds.). The Potter Cove coastal ecosystem, Antarctica: synopsis of research performed within the frame of the Argentinean - German cooperation at the Dallmann Laboratory and Jubany Station. Berlin, Polarforschung, p. 59-66.

Schloss, I.R., Abele, D., Moreau, S., Demers, S., Bers, A.V., González, O. \& Ferreyra, G.A. 2012. Response of phytoplankton dynamics to 19year (1991-2009) climate trends in Potter Cove (Antarctica). Journal of Marine Systems, 92(1): 53-66.

Schowengerdt, R.A. 2007. Remote Sensing Models and Methods for Image Processing. Arizona, Academic Press, 558p.

Schulz, F., Winkler, J.B. \& Kappen, L. 1998. Components of terrestrial vegetation, pattern and processes. Berichte zur Polarforschung, 4(299): 54-58.

Schuster, K.C. 2008. Impact of human and conspecific disturbance on behaviou and heart rate of incubating Adélie penguins (Pygoscelis adeliae). In: Wiencke, C., Ferreyra, G., Arntz, W. \& Rinaldi, C. (Eds.). The Potter Cove coastal ecosystem, Antarctica: synopsis of research performed within the frame of the Argentinean German cooperation at the Dallmann Laboratory and Jubany Station. Berlin, Polarforschung, p. 373-381.

Slaymaker, 0. 2009. Proglacial, periglacial or paraglacial? In: Knight, J. \& Harrison, S. (Eds.). Periglacial and Paraglacial Processes and Environments. London, Geological Society, p. 71-84.

Tatur, A. 2002. Ornithogenic Ecosystems in the Maritime Antarctic - Formation, Development and Disintegration. In: Beyer, L. \& Bölter, M. (Eds.). Geoecology of Antarctic Ice-Free Coastal Landscapes. New York, Springer, p. 161-186.

Turner, J., Barrand, N., Bracegirdle, T., Convey, P., Hodgson, D., Jarvis, M., Jenkins, A., Marshall, G., Meredith, M., Roscoe, H. \& Shanklin, J. 2013. Antarctic climate change and the environment: an update. Polar Record, 50(3): 1-23.

Turner, J., Colwell, S.R., Marshall, G.J., LachlanCope, T.A., Carleton, A.M., Jones, P.D., Lagun, V., Reid, P.A. \& Iagovkina, S. 2005. Antarctic climate change during the last 50 years. International Journal of Climatology, 25(3): 279-294.

Vieira, G., Mora, C., Pina, P. \& Schaefer. C.E.R. 2014. A proxy for snow cover and winter ground surface cooling: Mapping Usnea sp. communities using high resolution remote sensing imagery (Maritime Antarctica). Geomorphology, 225(15): 69-75.

Wunderle, S., Saurer, H. \& Gossmann, H. 1998. Meteorological conditions and snow cover dynamics on the Potter Peninsula, King George Island, Antarctica. In: Wiencke, C., Ferreyra, G., Arntz, W. \& Rinaldi, C. (Eds.). The Potter Cove coastal ecosystem, Antarctica: synopsis of research performed within the frame of the Argentinean - German cooperation at the Dallmann Laboratory and Jubany Station. Berlin, Polarforschung, p. 15-27. 